\title{
Situating Risk, Sexual Health and HIV/AIDS: Implications for (Non-) Negotiation of Safer Sex among Young People in North Central Nigeria
}

\author{
Ekundayo B. Babatunde ${ }^{1,}$ Babatunde E. Durowaiye ${ }^{2}$ \\ '(Department of Sociology, Landmark University, Omu-Aran, Kwara State, Nigeria) \\ ${ }_{2}^{2}$ (Department of Sociology, Landmark University, Omu-Aran,Kwara State, Nigeria)
}

\begin{abstract}
This research explores the contexts in which young people identified risks in terms of sexual activity that could result in HIV/AIDS, unwanted pregnancy or other outcomes injurious to their health. This qualitative study draws from 16 in-depth interviews and 10 focus groups through the voices of young women and men (aged 16-25) revealing the dimensions of their perception of sexual risk such as associated with having multiple sexual partners or casual sex and their construction of risk as related to unwanted pregnancy.

Beyond this, the young people tended to deploy different discursive frames within moral, gendered and expert discourses to define patterns of sexual practice perceived as 'safe' or 'risky' in their day-to-day interactions. The study concludes that intervention programmes that emphasize the A and B elements (Abstinence and Being faithful to one partner) as opposed to $C$ (condom use) were unhelpful for young people. Condom use was viewed by a majority of the young people as against their moral upbringing and further reinforced by religious mores and discourses condemning premarital sex for young people. Thus, while most interviewees viewed sexual activity as inevitable, they chose to engage in serial monogamous relations, associating condom use with promiscuity or prostitution.
\end{abstract}

Keywords: sexual risk; safer sex; negotiation; sexual health; HIV/AIDS; young people

\section{Introduction}

This study presents analysis of the various ways in which young people in the North central Nigeria were found to negotiate safer sexual practice, taking into account the competing social pressures affecting their negotiation of risk with respect to sexual health and HIV/AIDS. Specifically, it explores the meanings that young people attributed to sexual risk, the various discourses that contributed to their understanding of sexual health and the implications that these meanings might have for their capacity to negotiate safer sexual relationships. For instance, while both young women and young men appeared to have rejected the moral discourse that prescribed sexual abstinence for young people in their community, a majority still accepted the norm that viewed condom use within the same context as indecent or symbolizing immoral sexual practices.

There were also significant gender differences in the ways the young people constructed their notions of sexual uihealth risks. For instance, for most young men, the fear of HIV/AIDS appeared to have a major impact on decisions in favour of monogamous relationships, often resulting in serial monogamy. For their part, most young women appeared to be more concerned with the prevention of premarital pregnancy, due to the high level of stigma that was often attached to it locally.

This analysis draws on the social constructionist view of risk from a mostly Foucauldian perspective of discourse as an explanatory framework. This approach explains how people internalize and normalize particular forms of social behaviour as a type of self-regulation (Foucault, 1980, Mills, 2003). It provides explanations of the ways in which some dominant discourses might influence young people's notions of sexual risk; in particular, how they become subject to or resist certain opinions or beliefs and the strategies they adopt or reject in negotiating risk and maintaining their sexual health.

\section{Socio-Cultural Milieu and Young People's Sexuality}

The development of systematic (sociological and anthropological) approaches in recent decades has transformed the view of young people's sexual practices from one primarily concerned with biological activity to an explanation of cultural norms, values, beliefs and practices that places young people's sexuality within its social context.

For instance, Foucault (1980) argues that language has the power to influence complex behavioural patterns, because language and discourse (both verbal and non-verbal, and including silences) are key vehicles for producing knowledge, which itself is equated with power. Thus, both language and discourse lead to some practices being considered as normal and others as abnormal. Reviewing these arguments, one could observe 
that language and discourse constitute a broad cultural understanding of what is true and right, and provide social meanings to the complex worlds of social and sexual relationships.

In addition, Selikow (2004) observes the influence of social discursively promoted norms and ideologies that shape young people's sexuality and sexual practices within the social context of South Africa. It was observed that young South Africans were not considering the use of condoms, despite engaging in multiple sexual relationships and transactional sex. There was also found to be an existing norm of a social status that defined a 'real man' (locally referred to as ingagara) among young South Africans. This item of local discourse was popularly used for men of high potency, such that young men were commonly socialised to seek a variety of sexual partners, while young women were encouraged to keep multiple sexual partners in exchange for money and gifts.

In Nigeria, some social scientists have begun to pay more attention to gender and sexuality in exploring the discourses associated with sexual practices among young people. In a study conducted among rural adolescent boys in south-eastern Nigeria, Izugbara(2004) explored participants' notions of sex, sexuality and relationships. He observed that participants generally believed that boys should endeavour to have sex frequently and with different girls. He reported that infrequent sex was a major cause of "penile weakness, loss of male virility and penile malformation". In this sense, there was a strong discourse of male sexual desires as natural and instinctual, while masculinity was attached to male sexual potency.

Additionally, Smith (2004) reports that some social norms and cultural values have resulted in various contradictions in young people's sexual practices in eastern part of Nigeria: while the sampled respondents in this study engaged in premarital sex for different reasons, including socio-economic ones, condom use was considered suggestive of an immoral relationship. According to the local discourse among this group, condom use could also result in female infertility. In contrast, the 'educational discourse' among young people in school implied that premarital sexual activity was part of a desirable modern lifestyle and consonant with urban social values.

Furthermore, Lambert and Wood (2005) treat the themes of sex and sexual practices as subjects of 'silent discourse' or as being expressed through the use of euphemistic or indirect terms, so that sex is referred to as 'meeting' or 'heat'. Consequently, the introduction of sex education to young Indians in school is reported to have received a considerable level of resistance from parents, religious authorities and conservative political organizations, who asserted that the prevalence of HIV/AIDS among young Indians was an indication that western values had distorted the traditional norms guiding their moral practices. In the same study, a number of contrasts are apparent. For example, sexual intercourse in South Africa is constructed as a necessary condition of men's physical and mental health, while women's sexual practice and contraceptive use are regarded as 'womb dirtiness' and harmful to women's health. Within South Asian culture, however, sexual intercourse is perceived as an activity that weakens (male) bodily systems and reduces the accumulation of semen, so that avoidance of sexual practice will enhance physical strength and bodily health in men. In contrast, another discourse within the South Asian population (among truck drivers) is the belief that sexual intercourse provides a way of sanitizing the body and freeing the system of 'accumulated heat', which is itself considered dirty and physically unhealthy (Lambert et al., 2005).

To summarize this section, one could observe that the dominant discourses across different cultures and societies appear to work to reinforce unhealthy sexual practices among young people, a finding which the present study aims to confirm or refute within the Nigerian setting.

\section{Research Methods}

This study was conducted among young people in a rural-urban community known as Kabba situated in Kogi state, Nigeria ${ }^{1}$. Participants were selected through purposive and snowballing sampling techniques to generate data with the use of one-to-one in-depth interviews (IDIs) and focus-group discussions This paper is a part of an exploratory study of young people's sexual relationships in relation to the transmission of HIV within Nigerian socio-cultural contexts. The focus groups consist of 10 sessions, 5 sessions were held with the sampled young women and another 5 sessions with the young men in two selected schools and with the out of school group. For easy analysis, the sample was classified into two major groups, 'schoolers': those who currently attended school or had completed secondary (high) school: and 'non-schoolers: those who had never attended school or did not complete secondary school. Each group was further divided in the analysis into younger schoolers/non-schoolers aged 16-19 and older schoolers/non-schoolers aged 20-25.

Biographical details were elicited from participants at the beginning of each interview and focus group session. I followed the Ethical Guidelines for Sociological Research (2002) in conducting the study. Following approval

${ }^{1}$ Kabba is a small town in Kogi State ${ }^{1}$, Nigeria and the seat of the Kabba/Bunnu Local Government. The community lies at the intersection of roads from the state capital (Lokoja) and a number of other cities and towns. Kabba lies about 45 minutes drive from the tate capital and 3 hours from Abuja, the Federal Capital Territory of Nigeria. 
of the different stakeholders connected with the young group as well as the seeking the consent of the potential participants, the interviews were conducted at times and in places convenient to the respondents.

\subsection{Young people's construction of HIV and AIDS}

\section{Discussion of Major Findings}

The young people generally described HIV/AIDS as the most frightening sex-related problem in Kabba. Both female and male participants, particularly in the focus groups, described HIV/AIDS as 'dreadful', ' deadly' or a 'killer disease' and many referred to people in their community who they believed had died of AIDS. When the young people were asked in focus group sessions about what they knew about HIV/AIDS, its transmission and prevention, a majority shared views exemplified by the following responses:

HIV/AIDS is the most dreadful disease one could contract during sex and once a person gets infected with it, the person is doomed... I attended a few seminars in school ... then even on radio FM, they often mentioned the symptoms... [Female: aged 19, younger schooler]. schooler].

The fact that HIV/AIDS has no cure is what really baffled me ... [Female: aged 19, younger non-

HIV/AIDS is the most deadly infection... That's why it's good to maintain one's moral upbringing ... [Male: younger schooler, aged 17].

I think HIV is the worst disease ever. It destroys one's sexual wellbeing without a remedy and it's a shameful thing because everyone in this town will know that you're dying because of living an immoral lifestyle... [Male: older schooler aged 22].

I can say that people generally fear HIV/AIDS in this town because we all know that HIV/AIDS is real and is incurable... [Male: older non-schooler, age 23].

The above data are representative of the fears which the young people expressed about the reality of HIV/AIDS in their community. Most participants, regardless of gender, age and education, constructed HIV/AIDS as a frightening threat. As revealed by their accounts, the young people generally conceived HIV/AIDS as 'dreadful, 'incurable', 'shameful', the 'worst disease ever' and a disease which "destroys one's sexual wellbeing without a remedy". In particular, the above excerpts reveal that HIV/AIDS was highly stigmatised in the community and was generally constructed as a punishment for those living immoral lifestyles. This explains why the young people tended to focus on the visible outcomes of HIV/AIDS in their descriptions of those infected with HIV or living with AIDS, referring to their physical appearance or health status. For most of these young people, those infected with HIV or living with AIDS were characterized by loss of weight, weakness of the body and persistent illness.

It was further observed that most of the young people appeared not to be able to make an accurate distinction between HIV and AIDS in terms of understanding HIV as the infection that causes AIDS. This can be observed some of the responses highlighted above, describing both HIV and AIDS as an infection or disease mainly transmitted through sexual intercourse. More importantly, a dominant belief among the young people was that they were not at risk of HIV infection, indicated by identifying those engaging in casual sex or immoral lifestyles as those being at particular risk of HIV infection. Specifically, a number of young people in the interviews and focus groups made reference to three different groups whom they assumed to be at high risk of contracting HIV. This can be observed in the following quotes:

...you can easily tell a wayward girl from her physical appearance -Some of them just came back from cities like Lagos or Abuja where they've been prostituting... they dress waywardly...Some of them even go after okada men just to make money... [Interview: Male: older non-schooler, aged 25].

I fear that killer disease, that's why I police my girlfriend everywhere and I don't go for city girls... [Why avoid them?] Ah, [smile] they are danger zones for men and you know, AIDS has no cure ... See, HIV/AIDS did not originate from Kabba, that's why our people call it arun gbajumo, that is, a disease of those who are exposed, you know, like those city girls... [Do you use condom always?] Not every time, but I'm very careful with the type of woman I date [Older non-schooler, aged 24].

I have no fear of getting infected with AIDS ... I'm not one of onihan yhin sagbere [those prostitutes] or onihan yhin se shina [irresponsible or promiscuous]... [Female: Younger non- schooler, 18].

it's always good to maintain a moral lifestyle...if you happened to be sick ..., people might start thinking that you're not decent enough... [Focus group: Older schooler, female, aged 22].

Those guys that visit hotels to sleep with prostitutes are in danger of HIV/AIDS because most of those prostitutes are infected with HIV/AIDS... [Focus group: Older non-schooler, male, aged 20].

...to be sure you're protected, you won't go out with some people like an okada man ${ }^{2} . .$. Those thinking that you were already infected with HIV/AIDS... because they don't see you as guys smoke [and]

${ }^{2}$ Men in motorcycle business. 
drink ... anyhow, they are so rough and reckless in dating girls, reckless in everything they do, just like in their driving.... [Focus group: Older non-schooler, female, aged 24].

As these narratives imply, a majority of respondents conceptualized the risk of HIV/AIDS and their notions of safer sex within dominant moral discourses deeply entrenched in their local context, equating HIV infection with deviant sexual morality. As described above, the young people were consistent in making references to particular groups of people such as those in the transport business (motorcyclists), commercial sex workers and a group of young women identified as 'city girls'. These groups of people were generally believed to be living 'carefree' lifestyles, such as having many partners and casual sex. This subjective conception of risk and of high risk groups was clearly articulated by a number of them, viewing having a sexual relationship with an okada man as risky, due to the popular notion of men in the motorcycle business as often drunk, riding recklessly, smoking and lacking stable relationships. Similarly, many young men assumed that young women who had travelled to cities were 'wayward', that sexual relationships with them would be totally unsafe and that they could be recognized by their appearance, notably their dress. In addition, some of the young men constructed HIV/AIDS as arun gbajumo, that is, a disease of those who have been exposed to city lifestyles, while for some young women, AIDS was a disease of oli shina, that is, people living reckless lifestyles, or of prostitutes.

It can thus be said that the young people understood risk in terms of particular patterns of social and sexual behaviour exhibited by individuals or what certain groups of people choose to do in their lives. It is particularly evident that the young people's notions of risk as regards HIV infection were largely influenced by the prevailing social norms and the cultural contexts that prescribed the codes of morally appropriate sexual behaviour. Thus, when individuals or groups deployed the power of deviance (Foucault, 1980) by acting contrary to the restricting moral norm, such as by dressing freely, they would be labeled by other members of the community as risky. An important implication of the young people's subjective conception of risk is that HIV/AIDS risk was mainly attributed to particular group of people by virtue of their social behaviour, rather than whether they engaged in safe sexual practices such as condom use. A widespread belief was observed among young Kabbarian women and men that avoiding sexual relations with commercial sex workers, okada men and those whom they referred to as city girls would serve to protect them from contracting HIV, rather than considering the use of condoms.

Such accounts are similar to those reported in many other studies, where certain discredited groups of people, by reason of their occupation, habits, age, sexual identity or number of sexual partners have been classified as high risk. For instance, in the UK and US contexts, most of the early AIDS researchers and policymakers are reported to have assumed that HIV/AIDS was mainly transmitted by intravenous drug users, commercial sex workers and gay people, while heterosexual couples were perceived as being at less risk or even immune to HIV infection (Weeks, 1993, Schillers et al., 1994, Bloor, 1995, Brown, 2000). Similarly, among the middle-class in Thailand, Fordham (2001) has observed a discourse of "morality and normativity". In light of the existing discourses, HIV/AIDS risk was mainly attributed to some marginalised groups of people such as commercial sex workers, homosexuals and injecting drug users, who were often constructed as immoral and culturally deviant, and treated differently from the general or 'normal' population. These groups were also considered at high risk of HIV/AIDS, making them a central focus of prevention programmes (Fordham, 2001). More recently, Shoveller and Johnson (2006) have also reported that young Canadians often employed discourses dominant within their society to promote certain forms of sexual behaviour that they constructed as sexually safe, while constructing others whose patterns of sexual behaviour did not conform with the norm as e partner?] Well, we know ourselves well enough in this town, so I can tell a decent girl... [Do you have a trusted partner?] Em, I can say yes, at least for now...some condoms have tiny holes and may not guarantee $100 \%$ safety (FGD: older schooler, aged 25).

I'm a member of the Anti-AIDS Club here in our school,through that I got to know that condoms are not $100 \%$ reliable... That's why it's not safe when you're keeping chains of men ... Keeping to one trusted partner is more fitting because with one man, your safety is sure, [So, have you got a trusted man?] ...shy! yeah, recently... [So you won't have to use a condom?] It's okay if he decides to use one, atleast to prevent pregnancy ... (Female interviewee, younger schooler, aged 19).

The above data exemplified the general notions of sexual risk and sexual safety as expressed by a number of young people in the sample. Respondents of both genders recounted how they became aware of the risk involved in having multiple partners through the health talks and seminars that they had attended in the Anti-AIDS $\mathrm{Club}^{3}$. As the accounts reveal, both male and female interviewees tended to think that safer sex

\footnotetext{
${ }^{3}$ The Anti-AIDS Club seems to have gained high acceptability, as almost all the schoolers indicated that they had learnt about HIV/AIDS through it. Participants explained that the Club is a voluntary organization coordinated by some Youth Corps members, recent graduates in their compulsory one-year National Youth Service Corps programme. These particular Corps members had been posted to Kabba to serve in some of the secondary schools for a period of one year. They collaborated with a particular NGO on HIV/AIDS prevention to innovate the Anti-AIDS Club as their contribution to the development of the community during their period of service.
} 
could best be achieved by maintaining a sexual relationship with a single partner whom they considered trustworthy. Such views highlight the dominant influence of the expert discourse popularly known as the ABC strategy of AIDS prevention, an NGO intervention programme seeking to encourage young people, particularly at school, to consider three methods of preventing HIV infection: abstinence, being faithfulness to one partner and condom use. As highlighted above, the $\mathrm{ABC}$ discourse appeared to be reinforcing the religious norms and moral values of this particular culture. While the A and B parts of the slogan attempted to discourage young people from engaging in premarital sex and to favour monogamous relationships as the ideal form of courtship and marriage, the $\mathrm{C}$ element was focused on convincing them that condom use lacked total safety and reliability. This was observed from the manner in which nearly all the young women and men repeatedly expressed lack of confidence in the use of condoms, based on the seminars and health talks that they had attended. As some of them put it, "a condom does not guarantee one hundred percent safety". It appears from the narratives of the respondents that the $\mathrm{ABC}$ discourse had impacted on their understanding of what patterns of sexual practice were considered risky or sexually safe. The young women obviously lacked knowledge that being faithful to one partner does not really provide them the necessary safety. Thus, rather considering the use of condom, they consistently expressed a fear of contracting HIV through multiple partners and constructed monogamous relations as sexually safe.

Similarly, there was a prevailing moral and safer sex discourse within the cultural environment of these young people by which men who engaged in multiple sexual relations were regarded as oli shina, that is, irresponsible or lacking a sense of decency, while women with multiple partners were referred to as alagbere or asewo, meaning whores or prostitutes. Such people were also categorized among those at risk of HIV/AIDS, with a majority viewing their monogamous relationships not only as a means of protecting themselves from HIV/AIDS but also as a symbol of their decency or morality. In particular, the young people's belief that having a single partner was a means of ensuring safety in the context of sexual relationships was found to be reinforced by a popular safer sex discourse, oju kan la da ni, which literarily suggests keeping to one partner is an ideal behaviour.

I broke up with two girls in the past when I realized that they were not trustworthy. The last girl was a typical prostitute. She started getting close to those corrupt girls that run after rich men... Now that I'm a good Christian, I know it's sinful to be promiscuous, so I try to be as decent as possible, you know, for my own good... [Interview: Male: older non-schooler, aged 20].

In fact, many have been infected because they are not decent enough to remain faithful to their only partner... I don't believe in running after different men... I would only change my mind about him if I discovered that he's cheating on me... [Older schooler, 24].

I have no fear of getting infected with AIDS because I pray daily for safety... I have only one guy in my life and that's it. [Are you his only girlfriend?] Yes, except he decided to change his mind [Smiles]... [Do you normally use a condom?] Em, well, there are times he does but at times we don't... [Female: Younger nonschooler, 18].

I've been careless in the past but now I'm closer to God ... I have only one girl now... You know, it's now one girl at a time, but the major problem is finding someone to trust... [Do you use a condom in your new relationship?]... Not every time, that's why I look for a decent girl ...[Older schooler, aged 21].

The above responses illustrate different ways in which a number of male and female interviewees conceptualized multiple partnering as risky to their sexual health. It is interesting to note that most respondents expressed the desire to maintain one trusted partner, whom they described as 'decent'. However, if they had reasons to end one relationship for another they appeared to give little consideration to the risk of transmission of HIV infection through unprotected sex with the new partner. This apart, many young men considered most 'girls' as untrustworthy, based on the notion that they were keeping company with those identified as 'risky people'; thus, their sexual stories revolved around how they would dissolve one relationship to begin another. The central point of these narratives is that the young men tended to engage in unprotected sex in their serial monogamous relations, even when they had little or no knowledge of the HIV status of their successive partners. Similarly, for the young women, their notion of sexual risk was conceptualized in terms of having multiple sexual relations, regardless of protection. Moreover, they viewed monogamous relationships as more fitting, as helping to maintain a good reputation, or as ensuring safety. However, as with the young men's accounts, young women like those cited above also gave reasons that could lead them to decide to dissolve one relationship and begin another. An important finding here is that despite their sexual stories which revolved around dissolving and starting new relationships, both young men and young women tended to disregard the use of condoms as a means of ensuring safer sex, in the belief that they were not personally at risk of HIV infection.

Further, the young people's responses to questions about sexual risk and safety revealed the extent to which their religious beliefs also acted as powerful influences on their sense of safety with respect to their sexual practices. For instance, older schooler commented that prayer could save him from being infected with HIV, even after he had engaged in unprotected sex. It could also be observed that he embraced the Christian 
norms that expected followers to live 'decent' lifestyles, and constructed multiple sexual relations as 'sinful' or 'against the will of God'. This made him resolve to keep to one partner rather than having multiple partners. Other respondents stated that they had changed their behaviour from engaging in sexual practices with multiple partners to having monogamous relations because of the moral teachings they had received from their religious environment. For most participants, this meant the Christian religion and particularly the Pentecostal churches, whose followers defined prostitution as sinful and unacceptable before God. As the majority of the young people were Christians, such moral discourse related to monogamous marriage was a well established norm and a governing principle for them, leading them to consider a single partner as less risky, even at the level of premarital relationships.

The above findings confirm that young people equated risk with having multiple sexual partners, based on specific cultural and religious norms which defined abstinence or monogamous relationships as the acceptable pattern of sexual practice, through various moral discourses. This was further reinforced by expert knowledge typified by the $\mathrm{ABC}$ discourse, which young people constructed as the appropriate way of avoiding the risk of HIV/AIDS. However, the results of this study reveal that the $\mathrm{ABC}$ discourse alone was often ineffective, as it merely served to reinforce the traditional and religious views of young people's sexuality, rather than providing sex education that disentangled sexual health issues from moral ones.

\subsection{Risk of unwanted pregnancy}

A specific gender dimension to conceptions of risk among the young people was the view that unprotected sex is most risky for young women, due to the possibility of unplanned pregnancy. As indicated by the responses of most female participants in this study, premarital pregnancy is viewed as taboo within the wider community and strongly stigmatizes the young mothers and their families. Thus, a majority of young females, both schoolers and non-schoolers, constructed the possibility of becoming pregnant as a more immediate sexual risk within a monogamous relationship than that of contracting HIV. This is reflected in their responses when they were asked about their perceptions of who should initiate the use of a condom or any other means of protection in a relationship:

... men don't get pregnant or drop out of school... a woman must take precaution... because of pregnancy ... when your friends are getting married you're there watching different ceremonies because nobody wants to marry a tokunbo [FGD: younger-schooler, aged 19].

You know when you become pregnant outside wedlock, it means you'll remain unhappy and subject of ridicule among friends and neighbours. You know, people will see you as not having a sense of moral upbringing... The worst thing is that if you try to get rid of it, it may damage your womb or even lead to death... So prevention is better that cure... [Interview: Older schooler, aged 24].

Well, we normally do it [have sex] because we're in love. [Do you use a condom?] I don't really bother him about condoms and all that... I learnt about the use of Postinor from a friend so that I can protect myself from unplanned pregnancy, which is my greatest fear. [How about HIV/AIDS?] I don't go out with just any man, I have my own man... [Younger non-schooler, aged 19].

I have a friend that became pregnant during our second year in school. She dropped out of school and each time I see her she always tells me how lonely life has been for her. No man wants to marry you as after one... [Younger schooler, aged 18].

These responses suggest that the fear of premarital pregnancy often overshadowed young women's concern about the risk of contracting HIV. Having established in the previous section that most female participants did not view themselves to be at risk of HIV/AIDS, in the belief that having a single and trusted partner would not put them at risk, it can be observed from the above narratives that their conception of risk and protected sex was limited to avoiding unwanted pregnancy, rather than HIV infection.

It is evident from the young women's accounts that a high level of stigma was associated with premarital pregnancy in the community and that young women in that condition were usually the subject of ridicule, rejection and social ostracism. In this particular culture, young women were expected to adhere to the approved moral values of decency and to safeguard their reputations, such as by remaining chaste until marriage. For instance, some of the participants indicate that any young woman having a child outside wedlock would be seen as being immoral and tokunbo, a local expression meaning 'of second hand value' or 'past one's best'. Another popular phrase, 'after one', is the way by which members of their community referred to those who had borne a child outside marriage. The narratives of these young women indicated that such labels would often limit their chances of securing a future husband and of celebrating the marriage which, according to many young women in the FGD would accord them and their families a reputable status in the community.

Other young women narrated their experiences of being abandoned and subject of gossip among friends, families and neighbours, and of having to drop out of apprenticeships, due to unplanned pregnancy: 
I was careless for one day and got pregnant... I lost many of my friends, couldn't complete my fashion design course and suffered abandonment... He doesn't want to see me and even my family members are not happy with me because I brought shame on them... [Interview: Younger non-schooler, aged 19].

I've been going through hell since I became pregnant. In fact, I wanted to get rid of it, but it never worked, ... [Interview: Older non-schooler, aged 23].

Another female participant described the stress and physical pain she endured while pregnant, using phrases such as 'life was miserable', 'lonely' and 'the worst moment ever':

It was the worst moment I ever experienced in my life. The guy denied the pregnancy, his parents supported him and started insulting me, telling me that they trusted their son... and the most painful aspect was my parents... They treated me as if I was a prostitute... At one point my dad started beating me and saying that I brought shame to his family... My mum was bitter with me... But thank God, at about three months I don't know what happened I just started bleeding, when we got to the hospital, the doctor said I had a miscarriage... So I learnt a big lesson - [Interview: Younger older schooler, 19].

The quotations above provide examples of the negative experiences of pregnant youngsters and the discrimination that they encountered within their families and the community. Such accounts suggest that young women owned the responsibility for safer sex in this context to avoid moral condemnation within the family and the wider community. Not surprisingly, one the female respondents was relieved when she realized that she had lost her pregnancy. In one of the accounts quoted earlier, a students who became pregnant were expelled from school, and another been made to end her apprenticeship. Such stigmatizing experiences led the young women to describe their situation as 'hell' or 'the worst moment ever' and to express shame and regret. This explains the decision of many young women to use oral contraceptives and their association of protected sex with insurance against premarital pregnancy rather than HIV/AIDS. Moreover, in most of the reported cases of unmarried pregnancy, the male partners ended the relationship and were not often compelled to accept any form of responsibility; nor were they subject to public stigma.

These findings suggest that young people in this study conceptualized sexual health in relation to avoiding risks related to HIV infection and unwanted pregnancy. However, it could be observed that HIV/AIDS was seen a depersonalized risk, as they generally constructed their notions of not at risk of HIV/AIDS. In this sense, they generally expressed the view that sexual relationships with multiple partners or those believed to be promiscuous would increase their risk of becoming infected with HIV. Such accounts are similar to those reported in many other studies, where young people have equated single partnering to safer sex.

\subsection{Risk of total abstinence from sex or late sexual debut}

The final theme that emerges from the young people, specifically the young women's accounts is their conception of total abstinence from sex or late sexual debut as a risk to their reproductive capacities. In contrast to the restrictive norms and taboos around young women's sexuality and premarital pregnancy in this culture, there was evidence of a conflicting peer norm among young Kabbarian women that late sexual debut could pose a risk to their fertility. This opinion was shared in a particular focus group of apprentices aged 16 to 19:

I heard from a friend that one could be barren if one decides to wait till marriage before having sex, but I don't really know if that's the truth... [Younger non-schooler, 17].

Well, I've heard about it... [From who?] I was just listening to some guys that came to our shop... They said as a woman, the first sexual intercourse you have will open your reproductive system... kind of opening some tight nerves... so if you're not intending to marry early, then you need to have sex at least once, to open up your system, otherwise you may be barren for life... [Did you believe them?] Well, I think it's true because when you take note of our mothers, they all started having sex early because they married early, you know like 16 or 17 years, and that's why they all bear children. You can hardly find any one of them that is barren, while we have many ladies now in our generation that are unable to bear fruits [children] in their marriage...(Younger non-schooler, aged 17)

[Nodding] Yeah, my mum said she married at about 16 ...but it's really confusing... (Younger nonschooler aged 18)

.... at the latest by age 20, you need sex to sensitize the body - otherwise it's like risking ones future... And you know in our place if you don't have a child you're doomed because your husband will replace you with another woman...then women are most fertile when at young age... That's why some of our mates get pregnant so easily when they get close [have sex], while we have some older women who are married and still praying to God for a child... (Younger non-schooler aged 19)

[Nodding in agreement with Dami].

Similar comments were recorded in interviews with two young women:

He actually suggested it... He said if I remain a virgin for too long, I may not be able to have a child later, so I became confused, because I've promised myself that I will maintain a moral lifestyle, to remain a 
virgin until I'm married. But again, I don't want to be a barren woman later...and that was how we started... [Female: older non-schooler, aged 23].

...That was about 4 years ago... I lost my virginity to him because he told me that it's better for me to have sex so that I don't become barren later in life... I was so confused because I don't want to lose my virginity to some one that will not marry me... Then I was afraid of sex and again I don't really like many things about this guy, but somehow I asked myself what if it's actually true, so I decided to play safe by agreeing with him ...I later learnt that it wasn't it wasn't true...[Older schooler, aged 24].

However, only one male respondent expressed similar views:

To me, sex is not all about men. A woman also needs to have sex to open up her system so that she can be fertile in life... [How?]...Ah, a woman should have sex to sensitize her body, otherwise she may not be able to conceive later. [Where did you hear that?] I heard through a friend, an older friend of mine... [Male: older non-schooler, aged 24].

As illustrated above, there was an existing sexual discourse among a group of young apprentices in relation to the risk associated with late sexual debut or total abstinence from sex. Their notion of sexual risk was based on the assumption that women need to be sexually experienced at a young age as a way of stimulating or enhancing their reproductive systems so that they will be able to bear children when they eventually settle down in marriage. Phrases such as "it's like opening some tight nerves..." or "to sensitize the body" are typical illustrations of the peer norm that constructed first sexual intercourse as a way of enhancing the reproductive capacity of a woman. A young woman above, explained how she became confused and worried about not wanting to lose her virginity for moral reasons, while at the same time considering the need to engage in sex to ensure her fertility in later years. Such findings suggest that the non-schoolers were more subject than their educated peers to myths and misconceptions about what would constitute risky or safer sex.

This finding has obvious implications for young women's sexual agency. For instance, based on the central importance associated with procreation in this particular culture, such a prevailing norm might encourage young women's involvement in early sexual practice, even when they have limited access to knowledge of means of achieving safer sexual practice. Izugbara (2001) reports a similar finding of early sexual debut among young people in Eastern Nigeria, having observed that most of the respondents had no knowledge of safer sex, particularly the use of condoms, even though they professed to having begun sexual relationships. Another implication of the young women's accounts quoted above is that they might be cajoled into engaging in sex that was unwanted or with an unwanted partner. This is exemplified in one of the above statements "I don't really like many things about this guy... but I decided to play safe by agreeing with him..." It would appear that despite her lack of emotional attachment or intimacy with her partner, the young woman decided to engage in sexual intercourse with him to avoid the perceived risk of infertility.

It is important to indicate that the conceptions of risk and the sexual practices of the young women in the present study reveal that they often experienced contradictory norms and tensions about what pattern of sexual activities to engage in, when and with whom, particularly regarding the ways in which their generational, economic, religious, traditional and dominant discourses impacted on their sexual lives.

\section{Conclusion}

This paper unfolds the various dimensions of perception of sexual risk among a sample of Nigerian young group. Analysis of the young people's accounts indicates that HIV/AIDS was constructed as a moral issue and connected with city life and modern lifestyles. This perception was found to have clouded young people's understanding of what safer sex entails and of the need to engage in safer sexual practices such as the use of condoms.

It was also found in this study that the various intervention programmes for young people were unhelpful in emphasising the $\mathrm{ABC}$ strategy of HIV/AIDS prevention. It was found that more emphasis appeared to be placed on the A and B elements (abstinence and faithfulness to one partener) as opposed to C (condom use), such that while most interviewees viewed sexual activity as inevitable, they chose to rely on having one partner at a time, associating condom use with promiscuous partners or prostitutes. Moreover, condom use was viewed by a majority of the young people as against their moral upbringing and merely possessing condoms was seen as against the norm. This was reinforced by religious mores and discourses condemning premarital sex for young people; thus, most young people sought to avoid being identified with condoms, to maintain their moral image and obedience to their religious teachings.

Based on the findings of the present study, it is useful to consider the sociological and anthropological thinking of authors such as Douglas, Giddens, Beck and Foucault, which emphasize the concept of risk as socially produced within specific social and cultural contexts(Lupton, 1999a, Lupton, 1999b, Tulloch et al., 2003). Specifically, Foucauldians claim that what counts as risk is what a particular society constructs as risky, and that risks are often culturally tied to 'deviant' groups and identities(Foucault, 1991, Lupton, 1999a), risk can 
be understood as a particular way of governing or shaping the behaviour of individuals or particular groups in a society, including some aspects of their social and sexual relationships(Foucault, 1991, Lupton, 1999a). One could therefore argue that risk is a core concept which specifies not only what patterns of behaviour (including social and sexual behaviour) are defined as risky, but also what particular social groups or identities are identified as being at risk and risky.

This theoretical perspective has three major implications for the present study. First, it suggests that young people's understanding of risk and of strategies available to avoid problems related to contracting HIV/AIDS is not strictly based on 'objective' knowledge but depends on the socio-cultural contexts within which such risk is identified. The second implication is the need to recognize that young people's understanding of a phenomenon like risk is mediated by dominant traditional or institutionalized practices that produce discourses, which in turn influence young people's understanding of risk and negotiations for safer sex. Thirdly, this approach suggests that the notion of sexual risk is specific to a particular context where risk is identified, depending on the knowledge prevailing at a particular time and on the way the people concerned are positioned within the institutional and broader cultural setting.

This study had addressed a significant gap in the field of young people's sexuality and their constructions of sexual health risk. Specifically, it moves beyond the large-scale quantitative analysis of sexual behaviour to reveal the various contexts that may contribute to young people's sexualities, including the contexts in which they construct and practice risky sexual practices.

Considering the manner in which young people in this study conceptualized sexual health risk as applying to certain groups of people, such as motorcyclists, for their 'reckless lifestyles', or young women commercializing sex, or those who have travelled to cities, there is an imperative need for programmes that enlighten young people about sexual health risk in terms of what people do in ensuring safer sexual practice or how individuals exercise their capacities for negotiating protected sex. Essentially, this means that young people need to be made aware of the need to change their perception of risk. It is through such initiatives that young people can understand the implication of engaging in unprotected sex in their serial monogamous relations (a common practice among young people in this study) and become conscious of the need to maintain healthy sexual lives.

\section{Acknowledgements}

Special thanks to all participants for sharing their stories with me.

\section{References}

[1]. Atuyambe, L., Mirembe, F., Johansson, A., Kirumira, E. K. \& FAXElid, E. (2005). ExPERIEnCES Of Pregnant AdolescentsVOICES From WaKiso District, UgANDA. AFRICAN HEALTH SCIENCES, 5(4):304-309.

[2]. Bloor, M. (1995). The Sociology of HIV Transmission. London: Sage.

[3]. British Sociological Association (2002). Statement of Ethical Practice of the British Sociological Association. Retrieved on 12 ${ }^{\text {th }}$ July 2007 on http://www.britsoc.co.uk/equality/Statement+Ethical+Practice.htm.

[4]. Brown, T. (2000). AIDS, risk and social governance. Social Science \& Medicine 50(7-8):1273-1284.

[5]. Fordham, G. (2001). Moral panic and the construction of national order: HIV/AIDS risk groups and moral boundaries in the creation of modern Thailand. Critique of Anthropology, 21(3):259-316.

[6]. Foucault, M. (1980). The History of Sexuality. (Vol. 3), New York, Pantheon.

[7]. Foucault, M. (Ed.) (1991). Governmentality. In G. Burchell, C. Gordon \& C. Miller (Eds.), The Foucault Effect: Studies in Governmentality (pp.87-104). Hemel Hempstead: Harvester Wheatsheaf.

[8]. Gilbert, H. (2004). Sexual development, social oppression, and local culture. Sexuality Research \& Social Policy, 1(3):58-70.

[9]. Harrison, A., Xaba, N. \& Kunene, P. (2001). Understanding safe sex: Gender narratives of HIV and pregnancy prevention by rural South African school-going youth. Reproductive Health Matters, 9(17):63-71.

[10]. Herdt, G. \& Stoller, R. J. (1990). Intimate communications: Erotica and the study of culture. New York: Columbia University Press.

[11]. Holland, J., Ramazanoglu, C., Sharpe, S. \& Thomson, R. (1998). The Male in the Head: Young People, Heterosexuality and Power. London: Tufnell Press.

[12]. Hulton, L. A., Cullen, R. \& Khalokho, S. W. (2000). Perceptions of the risks of sexual activity and their consequences among Ugandan adolescents. Studies in Family Planning, 31(1):35-46.

[13]. Izugbara, C. O. (2004). Notions of sex, sexuality and relationships among adolescent boys in rural South-East Nigeria. Sex Education, 4(1):63-79.

[14]. Lambert, H. \& Wood, K. (2005). A comparative analysis of communication about sex, health and sexual health in India and South Africa: Implications for HIV prevention. Culture, Health \& Sexuality, 7(6):527-541.

[15]. Lepani, K. (2005). Everything has come up to the open space: Talking about sex in an epidemic. Gender Relations Centre, Research School of Pacific and Asian Studies. Retrieved on $17^{\text {th }}$ January 2008 from http://rspas.anu.edu.augrc/publications/pdfs/.

[16]. Lupton, D. (1999a). Risk. London and New York: Routledge.

[17]. Lupton, D. (Ed.) (1999b). Risk and Socio-cultural Theory: New directions and perspectives. Cambridge: Cambridge University Press.

[18]. Mills, S. (2003). Michel Foucault. London and New York: Routledge.

[19]. Ng, C. J. \& Kamal, S. F. (2006). Bridging the gap between adolescent sexuality and HIV risk: the urban Malaysian perspective. Singapore Medical Journal, 47(6):482-490.

[20]. Oshi, C., Daniel, Nakalema, S. \& Oshi, L. L. (2004). Cultural and social aspects of HIV/AIDS sex education in secondary schools in Nigeria. Journal of Biosocial Science, 37:175-183. 
Situating Risk, Sexual Health and Hiv/Aids: Implications For (Non-) Negotiation of Safer Sex ....

[21]. Reddy, S. \& Dunne, M. (2007). Risking it: Young heterosexual femininities in South African context of HIV/AIDS. Sexualities, 10(2):159-172.

[22]. Schillers, N. G., Rystal, T. \& Ewellen, D. (1994). Risky business: The cultural construction of AIDS risk groups. Social Science of Medicine, 38:1337-1346.

[23]. Selikow, T. (2004). "We have our own special language." Language, sexuality and HIV / AIDS: A case study of youth in an urban township in South Africa. African Health Sciences, 4(2):102-108.

[24]. Shoveller, J. A. \& Johnson, J. L. (2006). Risky groups, risky behaviour, and risky persons: Dominating discourses on youth sexual health. Critical Public Health, 16(1):47-60.

[25]. Smith, D. J. (2004). Premarital sex, procreation, and HIV risk in Nigeria. Family Planning, 35(4):223-35.

[26]. Tulloch, J. \& Lupton, D. (2003). Risk and Everyday Life. London: Sage.

[27]. Weeks, J. (1993). AIDS and the regulation of sexuality. In V. Berridge, \& P. Strong, (Eds.), AIDS and Contemporary History (pp.17-35). Cambridge: Cambridge University Press. 